\title{
Obstetrical outcome of pregnancy complicated with first trimester bleeding and subchorionic hematoma
}

\author{
Kiran Agarwal, Ritu, Amrita Singh*, Anjali Singh, Amrita Mishra
} Department of Obstetrics and Gynecology, Lady Hardinge Medical College and Smt. Suchita Kriplani Hospital, New
Delhi, India

Received: 29 November 2019

Accepted: 13 December 2019

*Correspondence:

Dr. Amrita Singh,

E-mail: drsinghamrita@gmail.com

Copyright: () the author(s), publisher and licensee Medip Academy. This is an open-access article distributed under the terms of the Creative Commons Attribution Non-Commercial License, which permits unrestricted non-commercial use, distribution, and reproduction in any medium, provided the original work is properly cited.

\begin{abstract}
Background: First trimester bleeding complicates around 20-27\% of pregnancy. Objective of this study was to evaluate and compare the feto-maternal and pregnancy outcome in patients presenting with live pregnancy complicated with first trimester bleeding and subchorionic hematoma with those without subchorionic hematoma.

Methods: In this prospective observational study, based on ultrasonography, live pregnancies were categorized into two groups, first group having first trimester bleeding with subchorionic hematoma and second with first trimester bleeding only without any hematoma. They were evaluated for the end outcome of pregnancy in terms of abortion and continuation. Continued pregnancies were evaluated for antenatal complications, delivery and intrapartum events along with fetal outcomes.

Results: Outcome of pregnancies presenting with first trimester bleeding in terms of abortion was similar in both the groups, $22.8 \%$ and $21.5 \%$ with hematoma and without hematoma respectively. Incidence of preeclampsia was $11.4 \%$ and Fetal growth restriction was $7 \%$ in pregnancies with first trimester bleeding with hematoma and was significantly higher than those without hematoma which was $3.07 \%$ for preeclampsia and $3 \%$ for fetal growth restriction. Incidence of antepartum haemorrhage was higher in hematoma group but the result was not statistically significant. $20 \%$ pregnancies with first trimester bleeding with hematoma had preterm deliveries, while it was $7.7 \%$ in pregnancies without hematoma and the difference was statistically significant. Low birth weight had occurred in $20 \%$ of babies in first group of patients while $4.6 \%$ in second group, difference being statistically significant.

Conclusions: We found that live pregnancies with first trimester bleeding and subchorionic hematoma were associated with similar risk of miscarriage and antepartum haemorrhage while increased risk of preeclampsia, fetal growth restrictions, preterm birth, non-reassuring fetal heart pattern, caesarean delivery and low birth weight baby when compared to patients with first trimester bleeding without subchorionic hematoma. There was no difference in 5 minutes Apgar score and the NICU admission in both the groups.
\end{abstract}

Keywords: Feto-maternal outcome, First trimester bleeding, Miscarriage, Preeclampsia, Subchorionic haematoma

\section{INTRODUCTION}

First trimester bleeding complicates around $20-27 \%$ of pregnancy. ${ }^{1,2}$ Other than routine antenatal visits, bleeding in first trimester is the most important reason for the consultation. Contributary causes are complete, incomplete or threatened abortion, implantation bleeding, ectopic pregnancy, gestational trophoblastic diseases. The end result may be termination or continuation of pregnancy depending upon cause of bleeding and other maternal factors along with factors associated with conceptus. The pregnancies after first trimester bleeding 
may also progress to the period of viability and beyond. The ultrasound finding in patients with first trimester bleeding may show presence of subchorionic or retroplacental hematoma. Early a subchorionic hematoma is detected in pregnancy, higher is the rate of subsequent pregnancy failure. ${ }^{3}$ In literature, the incidence of first trimester intrauterine hematoma range from $1.3 \%$ to $40 \%{ }^{4-7}$

Presence of first trimester bleeding alone or with subchorionic hematoma increases the risk of abortion in the first 20 weeks of gestation and adverse maternal and perinatal outcomes in pregnancy continued beyond period of viability. Increased incidence of preeclampsia, antepartum hemorrhage, fetal growth restriction, and preterm delivery has been shown in studies. ${ }^{4,6,8,9}$ However Some studies have reported that women with Intrauterine hematoma were not at a higher risk of adverse pregnancy outcomes than those without Intrauterine hematoma. ${ }^{10,11}$

This research aimed to study pregnancy outcomes including maternal and perinatal outcomes in both the group of patients of first trimester bleeding with Subchorionic hematoma and first trimester bleeding without hematoma and to compare the results.

\section{METHODS}

This study was a prospective observational study conducted in the department of obstetrics and gynaecology, Lady Hardinge Medical College and Hospitals, New Delhi from November 2012 to March 2014. During this time duration patients coming with complains of first trimester bleeding were subjected to detailed ultrasound for live pregnancy or retained product of conception and for the presence of subchorionic hematoma. 163 patients presenting with first trimester bleeding were investigated for the study and were subjected for ultrasonography. 46 patients with USG showing non-viable pregnancy or retained product of conception were excluded from study. 117 patients with ultrasonologically confirmed live pregnancy at the time of presentation with first trimester bleeding were included in the study. On the basis of presence of either pre-existing diseases like hypertension, diabetes, chronic diseases, multiple pregnancy or history of recurrent pregnancy loss and bad obstetric history, 11 patients were excluded from study to obviate any influence on study outcome. 6 patients were lost to follow up and were excluded. Outcomes were studied in 100 patients. Of 100 patients studied, who presented with first trimester bleeding 35 had subchorionic hematoma and in 65 patients no such lesion was detected on ultrasound. These patients were followed up according to regular antenatal protocol. Outcomes measures for study were in terms of abortion at or before 20 weeks of gestational age, antenatal complications like preeclampsia, antepartum hemorrhage, fetal growth restriction, preterm birth, mode of delivery, intrapartum and postpartum complication and fetal outcomes.

\section{Statistical analysis}

Statistical analysis was done by SPSS 17 program. Continuous variable was presented as mean \pm SD and categorical variables were presented by absolute number and percentage. Chi-square or fisher's exact test was used for assessment. p-value less than 0.05 was considered statistically significant. In addition, the relative risk of adverse perinatal outcomes and the $95 \%$ confidence intervals were calculated.

\section{RESULTS}

\section{Demographic distribution}

Demographic details such as maternal age, race, ethnicity, body mass index and prior obstetric history in both hematoma and non-hematoma group were studied and showed similar characteristics in both the groups. Mean period of gestation $(n=100)$ at the time of presentation as bleeding was $9.13 \pm 1.9$ weeks. Mean age of patients $(n=100)$ was $25 \pm 2.84$ years with mean of parity $1.15 \pm 0.8$.

\section{End outcome of pregnancy}

Of 35 patients presenting with first trimester bleeding who had subchorionic hematoma $22.8 \%$ aborted and $77.1 \%$ continued pregnancy beyond 20 weeks. In patients with only first trimester bleeding and no hematoma, $21.5 \%$ aborted and $78.4 \%$ continued with pregnancy beyond 20 weeks. This showed similar adverse outcome of first trimester bleeding in both groups with or without hematoma in terms of abortion.

Table 1: End outcome of pregnancy.

\begin{tabular}{|lll|}
\hline Presentation & Abortion & Continuation \\
$\begin{array}{l}\text { First trimester bleeding } \\
\text { with hematoma }(\mathrm{n}=35)\end{array}$ & $8(22.8 \%)$ & $27(77.1 \%)$ \\
\hline $\begin{array}{l}\text { First trimester bleeding } \\
\text { without hematoma }(\mathrm{n}=65)\end{array}$ & $14(21.5 \%)$ & $51(78.4 \%)$ \\
\hline Total $(\mathbf{n = 1 0 0})$ & $\mathbf{2 2 ( \mathbf { 2 2 \% } )}$ & $\mathbf{7 8}(\mathbf{7 8 \%})$ \\
\hline
\end{tabular}

$\mathrm{p}$-value $=0.879$.

\section{Antenatal complications of pregnancy}

In all continued pregnancies antenatal complication like preeclampsia, antepartum haemorrhage and fetal growth restriction were studied. This study showed the incidence of preeclampsia was much higher $11.4 \%$ in pregnancies with first trimester bleeding with hematoma than in pregnancies with first trimester bleeding only by, that was $3.07 \%$. The result was statistically significant. Although the incidence of antepartum haemorrhage was higher $2.8 \%$ in first trimester bleeding with hematoma group than in pregnancies without hematoma $1.5 \%$, the result was not statistically significant. Occurrence of fetal growth restriction was analysed and it was found that $20 \%$ of pregnancies with first trimester bleeding with hematoma had fetal growth restriction as 
statistically significant.

Table 2: Antenatal complications of pregnancy.

\begin{tabular}{|llllll|}
\hline $\begin{array}{l}\text { Antenatal } \\
\text { complication }\end{array}$ & $\begin{array}{l}\text { First trimester } \\
\text { bleeding with } \\
\text { hematoma }(\mathbf{n}=\mathbf{3 5})\end{array}$ & $\begin{array}{l}\text { First trimester } \\
\text { bleeding without } \\
\text { hematoma }(\mathbf{n = 6 5})\end{array}$ & $\begin{array}{l}\text { Total cases } \\
(\mathbf{n = 1 0 0 )}\end{array}$ & Odd ratio (95\% CI) & p-value \\
\hline Preeclampsia & $4(11.4 \%)$ & $2(3.07 \%)$ & $6(6 \%)$ & $5.25(0.962-28.63)$ & $<0.001$ \\
\hline $\begin{array}{l}\text { Antepartun } \\
\text { haemorrhage }\end{array}$ & $1(2.8 \%)$ & $1(1.5 \%)$ & $2(2 \%)$ & $1.88(0.11-31.04)$ & 0.527 \\
\hline FGR & $7(20 \%)$ & $3(4.6 \%)$ & $10(10 \%)$ & $5.167(1.244-21.46)$ & $<0.001$ \\
\hline
\end{tabular}

Table 3: Delivery and intrapartum outcomes.

\begin{tabular}{|lllllll|}
\hline $\begin{array}{l}\text { Intrapartum } \\
\text { outcome }\end{array}$ & $\begin{array}{l}\text { First trimester } \\
\text { bleeding with } \\
\text { hematoma }(\mathbf{n}=\mathbf{3 5})\end{array}$ & $\begin{array}{l}\text { First trimester } \\
\text { bleeding without } \\
\text { hematoma }(\mathbf{n = 6 5 )}\end{array}$ & $\begin{array}{l}\text { Total cases } \\
(\mathbf{n = 1 0 0})\end{array}$ & Odd ratio $(\mathbf{9 5 \%}$ CI) & p-value \\
\hline Preterm delivery & $7(20 \%)$ & $5(7.7 \%)$ & $12(12 \%)$ & $3(0.87-10.28)$ & .007 \\
\hline $\begin{array}{l}\text { Non-reassuring fetal } \\
\text { heart rate pattern }\end{array}$ & $5(14.2 \%)$ & $3(4.6 \%)$ & $8(8 \%)$ & $3.44(0.77-15.37)$ & 0.007 \\
\hline Vaginal delivery & $15(42.8 \%)$ & $43(66.2 \%)$ & $58(58 \%)$ & $0.38(0.16-0.89)$ & $<0.024$ \\
\hline $\begin{array}{l}\text { Instrumental } \\
\text { vaginal delivery }\end{array}$ & $1(2.8 \%)$ & $1(1.5 \%)$ & $2(2 \%)$ & $1.88(0.11-31.04)$ & 0.527 \\
\hline Caesarean delivery & $4(11.4 \%)$ & $2(3 \%)$ & $6(6 \%)$ & $4.06(0.70-23.41)$ & 0.004 \\
\hline
\end{tabular}

Table 4: Fetal outcomes.

\begin{tabular}{|llllll|}
\hline Fetal outcome & $\begin{array}{l}\text { Incidence } \\
\text { First trimester } \\
\text { bleeding with } \\
\text { hematoma }(\mathbf{n = 3 5})\end{array}$ & $\begin{array}{l}\text { First trimester } \\
\text { bleeding without } \\
\text { hematoma }(\mathbf{n = 6 5 )}\end{array}$ & $\begin{array}{l}\text { Total cases } \\
(\mathbf{n = 1 0 0})\end{array}$ & Odd ratio $(\mathbf{9 5 \%}$ CI) & p-value \\
\hline Birth weight $<2.5 \mathrm{~kg}$ & $7(20 \%)$ & $3(4.6 \%)$ & $10(10 \%)$ & $5.167(1.244-21.46)$ & $<0.001$ \\
\hline Birth asphyxia & $3(8.6 \%)$ & $1(1.5 \%)$ & $4(4 \%)$ & $6.0(0.6-60.00)$ & $<0.007$ \\
\hline NICU admission & $1(2.8 \%)$ & $1(1.5 \%)$ & $2(2 \%)$ & $1.88(0.11-31.04)$ & 0.527 \\
\hline
\end{tabular}

\section{Delivery and intrapartum outcomes}

Delivery events and intrapartum outcomes were studied like preterm or term delivery, mode of delivery, Intrapartum fetal distress and asphyxia. 20\% pregnancies with First trimester bleeding with hematoma had preterm deliveries. Preterm delivery was only $7.7 \%$ in pregnancies with first trimester bleeding without hematoma and the difference was statistically significant. In patients with first trimester bleeding with hematoma $42.8 \%$ had normal vaginal delivery, $2.8 \%$ had instrumental vaginal delivery and $11.4 \%$ underwent caesarean delivery. Whereas in those without hematoma $43 \%$ had normal vaginal delivery, $1.5 \%$ had instrumental vaginal delivery and 3\% underwent caesarean delivery. Significantly higher caesarean delivery occurred in patients with first trimester bleeding with hematoma than in patients with first trimester bleeding without hematoma and the contributory causes were increased antenatal complications in hematoma group.

\section{Fetal outcomes}

In both groups of pregnancy continuation after first trimester bleeding with hematoma or without hematoma fetal outcomes were studied. Average birth weight in patients with pregnancy continuation after first trimester bleeding with hematoma was $2.6 \pm 0.24 \mathrm{~kg}$ and in group of patients with first trimester bleeding and no hematoma was $2.77 \pm 0.21 \mathrm{~kg}$. Statistically significant number of babies born with Birth weight less than $2.5 \mathrm{~kg}$, low birth weight were seen in the group of patients with first trimester bleeding with hematoma which was $20 \%$ than in those without hematoma which was $4.6 \%$. Incidence of birth asphyxia was higher in babies born to the patients with First trimester bleeding with hematoma than in other group of patients with first trimester bleeding with no hematoma, which was noted as $8.6 \%$ and $1.5 \%$ respectively. However, there was no significant difference in 5 minutes Apgar score and the NICU admission in the babies of either group. 


\section{DISCUSSION}

First trimester bleeding itself increases the risk of adverse outcome of pregnancy. In this study we studied the live pregnancies presenting with first trimester bleeding which were further evaluated by ultrasonography in regard to presence or absence of subchorionic hematoma and categorized into two groups, first trimester bleeding with hematoma and first trimester bleeding without hematoma. We evaluated whether presence of subchorionic hematoma in patients with first trimester bleeding was associated with adverse pregnancy outcome in terms of risk of abortion, antenatal complications like preeclampsia, antepartum haemorrhage, fetal growth restriction, intrapartum outcome like preterm birth, caesarean delivery, non-reassuring fetal heart rate pattern and neonatal outcomes.

In this study the mean gestational age of presentation of first trimester bleeding in this study was found to be at 91/7 week of gestational age. The occurrence of bleeding at this particular time was supported in the study done by Jauniaux $E$ et al. ${ }^{12}$ In their study Jauniaux $E$ et al reviewed the contribution of ultrasound imaging for understanding of the mechanisms leading to miscarriage in humans and demonstrated that the maternal circulation inside the placenta starts at the periphery at around 9 weeks of gestation and that this is associated with a physiological oxidative stress which could be the trigger for the formation of the placental membranes. Abnormal development of these membranes can result in subchorionic haemorrhage and threatened miscarriage with subsequent long-term consequences such as preterm rupture of the membranes and preterm labour, irrespective of the finding of a hematoma on ultrasound. This particularly happens at 9 weeks of gestational age.

In our study $22.8 \%$ in patients with first trimester bleeding with hematoma aborted as compared to $21.5 \%$ in those without hematoma. In the study done by Heller et al, a total of 434 first-trimester live singleton pregnancies between 6 and 11 weeks' gestational age with $\mathrm{SCH}$ were studied and the overall rate of first-trimester pregnancy failure was found to be $12.0 \%$ in the patients with subchorionic hematoma. ${ }^{3}$ Irina O. Bushtyrev et al studied 194 pregnant women of 6 to 12 weeks gestational age with viable embryo by 115 women with SCH (Group 1) and 79 apparently healthy pregnant women (Group 2). They reported the risk of pregnancy loss during 6 to 12 weeks gestational age to be $23 \%$ in Group 1 as compared to $5 \%$ of Group $2(\mathrm{P}<0.05)$ and during terms of 13 to 22 weeks it was observed in $2.6 \%$ patients. ${ }^{13}$ Emre $\mathrm{Y}$ et al in their retrospective cohort study assessed the effects of ultrasonographically detected subchorionic hematomas on pregnancy outcomes in patients with vaginal bleeding within the first half of pregnancy. They concluded that $29.5 \%$ pregnancies with subchorionic hematoma had miscarriage while that was $12.6 \%$ in pregnancies without subchorionic hematoma and the result was statistically significant $(\mathrm{P}=$ 0.010). The gestational age at miscarriage and the duration between first vaginal bleeding and miscarriage were similar between the groups. ${ }^{14}$ Peixoto et al in their retrospective cohort study found the incidence of intrauterine hematoma to be $4.5 \%$ (35 of 783 pregnancies) and also observed a higher proportion $(28.6 \%)$ of miscarriage in pregnancy with intrauterine hematoma than those without intrauterine hematoma $(10 \%){ }^{15}$

We found that first trimester bleeding with presence of subchorionic hematoma was associated with increased risk of preeclampsia, fetal growth restrictions, preterm birth, non-reassuring fetal heart rate pattern, caesarean delivery and low birth weight baby when compared to patients with first trimester bleeding without hematoma. This higher risk of antenatal complications and preterm birth the pregnancy with first trimester bleeding along with hematoma was reflected as occurrence of nonreassuring fetal heart rate pattern, increased rate of caesarean delivery and low birth weight, however there was no significant difference in 5 minutes Apgar score and the NICU admission, in the babies of either group.

In a systematic review and meta-analysis done by Tuuli et al. subchorionic hematoma was found to be associated with an increased risk of miscarriage (from $8.9 \%$ to $17.6 \%$ ), stillbirth (from $0.9 \%$ to $1.9 \%$,), abruptio placentae (from $0.7 \%$ to $3.6 \%$ ), preterm birth (from $10.1 \%$ to $13.6 \%$ ), and premature rupture of membranes (from $2.3 \%$ to $3.8 \%$ ) but not for small gestational age (OR 1.69, 95\% CI 0.89-3.19) and preeclampsia (OR 1.47, 95\% CI 0.37-5.89). ${ }^{16}$ Nagy et al, did a prospective study to compare perinatal outcomes in 187 pregnant women with intrauterine hematomas and 6488 controls in whom hematomas were not detected at first-trimester ultrasonographic examination and found an increased risk of pregnancy induced hypertension (RR2.1; CI1.5, 2.9) and preeclampsia (RR 4.0; CI 2.4, 6.7), abruption (RR 5.6; CI $2.8,11.1)$, preterm delivery (RR2.3; CI1.6, 3.2), fetal growth restriction (RR2.4; CI1.4, 4.1) in hematoma group. ${ }^{4}$

Another systematic review done by Saraswat et al, reported the association of first trimester bleeding and adverse maternal and perinatal. It was found that Women with threatened miscarriage had a significantly higher incidence of antepartum haemorrhage due to placenta previa or antepartum haemorrhage of unknown origin when compared with those without first-trimester bleeding. They were more likely to experience preterm premature rupture of membrane, preterm delivery and to have babies with intrauterine growth restriction. Firsttrimester bleeding was associated with significantly higher rates of perinatal mortality and low-birthweight babies. ${ }^{17}$ However in the study done by Pexioto et al, they reported no significant difference in regards to the prevalence of low birth weight (LBW; $\mathrm{p}=0.091)$, very LBW ( $\mathrm{p}=0.370)$, or extremely LBW $(\mathrm{p}=0.600)$ between cases with intrauterine hematoma and without intrauterine hematoma, the caesarean section rate $(68 \%$ versus $81 \%, \mathrm{p}=0.130)$, preterm delivery ( $16 \%$ versus $16 \%, \mathrm{p}>0.999)$, or the incidence of first-trimester vaginal bleeding ( $31 \%$ versus $20 \%, \mathrm{p}=0.130)$. 
The outcome measures of ongoing pregnancies such as gestational week at delivery, birth weight, and delivery route, were also similar both group of patients of first trimester bleeding with or without subchorionic hematoma. ${ }^{15}$ In this study, $20 \%$ pregnancies with first trimester bleeding with hematoma had preterm deliveries and $7.7 \%$ in pregnancies with first trimester bleeding without hematoma progressed to preterm delivery. Palatnik et al showed the occurrence of preterm birth to be more in patients with subchorionic hematoma and it was found to be $12.5 \%$. In multivariable regression, subchorionic hematoma remained associated with preterm birth even with cervical length entered into the equation as a covariate in their study. ${ }^{18}$

\section{CONCLUSION}

We found that live pregnancies with first trimester bleeding and subchorionic hematoma was associated with similar risk of miscarriage and Antepartum hemorrhage while increased risk of preeclampsia, fetal growth restrictions, preterm birth, non-reassuring fetal heart pattern, caesarean delivery and low birth weight baby when compared to patients with first trimester bleeding without subchorionic hematoma. There was no difference in 5 minutes Apgar score and the NICU admissions in both the groups.

\section{Funding: No funding sources}

Conflict of interest: None declared

Ethical approval: The study was approved by the Institutional Ethics Committee

\section{REFERENCES}

1. Farrell T, Owen, P. The significance of extrachorionic membrane separation in threatened miscarriage. Br J Obstet Gynaecol. 1996;103:926-8.

2. Hasan R, Baird DD, Herring AH, Olshan AF, Funk ML, Hartmann KE. Patterns and predictors of vaginal bleeding in the first trimester of pregnancy. Ann Epidemiol. 2010;20(7):524-31.

3. Heller HT, Asch EA, Durfee SM, Goldenson RP, Peters HE, Ginsburg ES, et al. Subchorionic hematoma: correlation of grading techniques with first-trimester pregnancy outcome. J Ultrasound Med. 2018;37(7):1725-32.

4. Nagy S, Bush M, Stone J, Lapinski R, Gardó S. Clinical significance of subchorionic and retroplacental hematomas detected in the first trimester of pregnancy. Orv Hetil. 2005;146(42):2157-61.

5. Pearlstone M, Baxi L. Subchorionic hematoma: a review. Obstet Gynecol Surv. 1993;48:65-8.
6. Ball RH, Ade CM, Schoenborn JA, Crane JP. The clinical significance of ultransonographically detected subchorionic hemorrhages. Am J Obstet Gynecol. 1996;174:996-1002.

7. Seki H, Kuromaki K, Takeda S, Kinoshita K. Persistent subchorionic hematoma with clinical symptoms until delivery. Int J Gynaecol Obstet. 1998;63:123-8.

8. Maso G, D'Ottavio G, De Seta F, Sartore A, Piccoli M, Mandruzzato G. First-trimester intrauterine hematoma and outcome of pregnancy. Obstet Gynecol. 2005;105:339-44.

9. Jauniaux E, Van Oppenraaij RH, Burton GJ. Obstetric outcome after early placental complications. Curr Opin Obstet Gynecol. 2010;22:452-7.

10. Falco P, Milano V, Pilu G, David C, Grisolia G, Rizzo N, et al. Sonography of pregnancies with firsttrimester bleeding and a viable embryo: a study of prognostic indicators by logistic regression analysis. Ultrasound Obstet Gynecol. 1996;7:165-9.

11. Tower CL, Regan L. Intrauterine haematomas in a recurrent miscarriage population. Hum Reprod. 2001;16:2005-7.

12. Jauniaux E, Johns J, Burton GJ. The role of ultrasound imaging in diagnosing and investigating early pregnancy failure. Ultrasound Obstet Gynecol. 2005;25(6):613-24.

13. Bushtyreva IO, Kuznetsova NB, Barinova VV, Kovaleva AV, Dmitrieva MP. Pregnancy outcomes in pregnant women with subchorionic hematoma. Int J Biomed. 2015;5(3):137-40.

14. Emre Y. The effects of subchorionic hematoma on pregnancy outcome in patients with threatened abortion. J Turk Ger Gynecol Assoc. 2014;15:239-42.

15. Peixoto AB, da Cunha Caldas TMR, Petrini CG, Romero ACP, Borges Júnior LE, Martins WP, et al. The impact of first-trimester intrauterine hematoma on adverse perinatal outcomes. Ultrasonography. 2018;37(4):330-6.

16. Tuuli MG, Norman SM, Odibo AO, Macones GA, Cahill AG. Perinatal outcomes in women with subchorionic hematoma: a systematic review and meta-analysis. Obstet Gynecol. 2011;117:1205-12.

17. Saraswat L, Bhattacharya S, Maheshwari A, Bhattacharya S. Maternal and perinatal outcome in women with threatened miscarriage in the first trimester: a systematic review. BJOG. 2010;117:24557.

18. Palatnik A, Grobman WA. The relationship between first-trimester subchorionic hematoma, cervical length, and preterm birth. Am J Obstet Gynecol. 2015;213:403.e1-4.

Cite this article as: Agarwal K, Ritu, Singh A, Singh A, Mishra A. Obstetrical outcome of pregnancy complicated with first trimester bleeding and subchorionic hematoma. Int J Reprod Contracept Obstet Gynecol 2020;9:23-7. 